\title{
Trainee led intensive care unit induction - an educational and quality improvement project
}

\author{
J Sumpter ${ }^{1}$, JD Wijesuriya ${ }^{1 *}$, R Mccomb', G Thomas-Black², A Achilleos ${ }^{1}$, A Connell ${ }^{2}$ \\ From ESICM LIVES 2015 \\ Berlin, Germany. 3-7 October 2015
}

\section{Introduction}

Under the leadership of the Faculty of Intensive Care Medicine, junior trainees from varied medical backgrounds are increasingly undertaking placements in Intensive Care Units (ICU) [1]. Unlike their predecessors, current trainees may have little prior training in advanced organ support (AOS), yet clinical responsibility may be high - a potential patient safety issue. Traditional seniordoctor led departmental induction may not rapidly adapt to the evolving requirements of current trainees [2].

\section{Objectives}

To assess the background, prior experience \& confidence at managing AOS in a cohort of trainees at our institution. Satisfaction with the standard departmental induction programme (IP1) was also assessed.

To design a new induction programme (IP2); novel in the sole use of current unit trainees for its development \& delivery, incorporating feedback from the initial assessment \& tailored to the needs trainees from differing medical backgrounds.

To assess trainee confidence/satisfaction following IP2 \& ensure project continuity.

\section{Methods}

Three written assessments were completed by two cohorts of trainees; Cohort 1 was assessed post IP1, Cohort 2 was assessed pre \& post IP2.

IP2 design was based on feedback from Cohort 1 \& took a structured approach to AOS, with five system-based presentations \& a written handbook. IP2 was delivered as a half-day of interactive lectures prior to Cohort 2 commencing placements in ICU.

${ }^{1}$ Whittington Hospital, Anaesthetics \& Intensive Care, London, United Kingdom

Full list of author information is available at the end of the article
Electronic copies of IP2 content were handed over to Cohort 2 to facilitate future delivery.

\section{Results}

Cohort $1(\mathrm{n}=8)$ included: $2 \times$ Core Medical trainees (CMT), $2 \times$ Emergency Medicine (EM) trainees \& $3 \times$ foundation trainees (FT); with prior ICM experience: $3 \times$ none, $5 \times<6$ months. Cohort $2(\mathrm{n}=6))$ included: $1 \times$ CMT, $3 \times$ FT \& $2 \times$ anaesthetic trainees (AT); with prior ICM experience $3 \times$ none, $2 \times<6$ months $\& 1 \times<$ 12 months.

Assessment responses graded 0-5 (poor-excellent) were mean averaged. Pre \& post IP2: trainee confidence at routine AOS management improved from 1.93 to 3.17; confidence at emergency AOS management improved from 2.17 to 3.33; understanding of AOS principles improved from 2.17 to 3.5 . Overall satisfaction with induction improved from 2.38 to 4.83 . (See Graph 1)

\section{Conclusions}

As ICM training expands in the UK, junior trainee confidence \& experience cannot be taken for granted. Induction programmes tailored for trainees of differing medical backgrounds can improve knowledge, confidence at managing AOS \& improve trainee satisfaction.

Such programmes need not be costly or consultant delivered. Our trainee led \& delivered programme resulted in improved levels of trainee confidence, high levels of satisfaction \& provided a legacy of teaching opportunity for trainees within the unit.

\section{Authors' details \\ ${ }^{1}$ Whittington Hospital, Anaesthetics \& Intensive Care, London, United Kingdom. ${ }^{2}$ University College London Hospital, London, United Kingdom.}

Published: 1 October 2015

\section{SpringerOpen $^{\odot}$}

C 2015 Sumpter et al.; This is an Open Access article distributed under the terms of the Creative Commons Attribution License (http:// creativecommons.org/licenses/by/4.0), which permits unrestricted use, distribution, and reproduction in any medium, provided the original work is properly cited. 
Graph ti: Pre / Post intervention (192) Trainee Responses

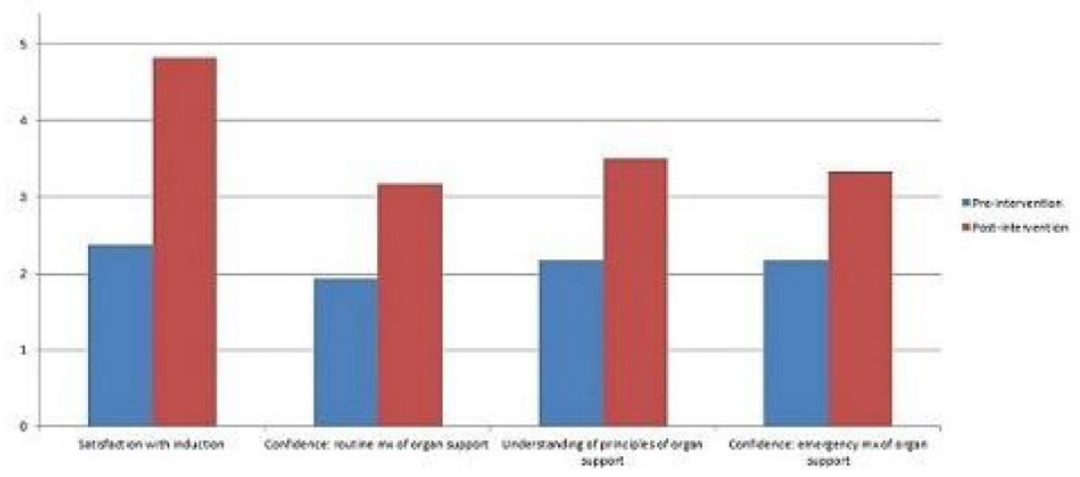

Figure 1

\section{References}

1. Nee P: The Faculty of Intensive Care Medicine. EMJ Supp 2011, 28(1(2)),

January.

2. Koshal S 1: Induction training for senior house officers in OMFS. Br Dent $J$ 2012, 213(2), Jul 27.

doi:10.1186/2197-425X-3-S1-A865

Cite this article as: Sumpter et al:: Trainee led intensive care unit

induction - an educational and quality improvement project. Intensive Care

Medicine Experimental 2015 3(Suppl 1):A865.

\section{Submit your manuscript to a SpringerOpen ${ }^{\mathcal{D}}$ journal and benefit from:}

- Convenient online submission

- Rigorous peer review

- Immediate publication on acceptance

- Open access: articles freely available online

- High visibility within the field

- Retaining the copyright to your article

Submit your next manuscript at $>$ springeropen.com 